\title{
A Mixed-Methods Study of Library Communication with Online Students and Faculty Members
}

\section{Nick Faulk and Emily Crist}

\begin{abstract}
To better understand, articulate, and improve the academic library's impact on online populations, this two-phase mixed-method study examines library communication with online students and faculty. In phase I, online focus group participants responded to vignettes illustrating library communication scenarios. Results from phase I informed the creation of a questionnaire for phase II. Results of both phases demonstrated that patrons' lack of knowledge about how and when to communicate with the library can serve as a communication barrier, that online patrons highly value being able to access librarians, and that a range of outreach strategies hold appeal.
\end{abstract}

\section{Introduction}

The 2017 Academic Library Impact report by the Association of College and Research Libraries identifies communicating the library's contributions as a key priority in studying the library's impact on academic success. ${ }^{1}$ This report recognizes several communication-oriented research questions in need of further study, including identifying the barriers in communication between the library and patrons such as students, faculty, and staff. Recommended actions for librarians to improve communication with stakeholders include identifying individuals who can advocate on the library's behalf and leveraging the fact that the library serves all student and faculty populations. Importantly, the report also notes the difficulty of providing best practices due to the vastly contextual nature of communication. However, the report suggests that libraries are failing to accurately communicate the breadth and value of services offered. ${ }^{2}$

For the sake of this paper, communication is defined as interactions between the library and college community stakeholders that result in increased knowledge of library services, resources, and programs. This communication consists of both one-way communication from the library to the community, and two-way communication between the library and the community. One-way communication includes outreach and marketing, including via the website and social media. Two-way communication consists of interactions through reference services, library advisory groups, and library instruction. While some of these modes, particularly library instruction, have many goals beyond communication itself, communication remains an

\footnotetext{
*Nick Faulk is Digital Learning Librarian and Emily Crist is Library Director, both at Champlain College; email: nfaulk@champlain.edu, ecrist@champlain.edu. This project was supported by an Academic Library Impact Research Grant from ACRL's Value of Academic Libraries committee. We would like to thank them for their dedication and investment in this work. (C2020 Nick Faulk and Emily Crist, Attribution-NonCommercial (https://creativecommons.org/licenses/by-nc/4.0/) CC BY-NC.
} 
essential component to the delivery of those activities such that they are worthy of conditional inclusion in the definition.

While communication is a complex issue within any campus group, it is an essential component in online environments. With a rapidly growing online student population, Champlain College in Burlington, Vermont provides a venue for studying the impacts of library communication on an online student and faculty community. Approximately 3,500 students study through Champlain College Online (compared with 2,100 students at Champlain College's residential campus). ${ }^{3}$ The online student population has grown several times over in the last five years. ${ }^{4}$ Students in the online division study in completely online, profession-oriented majors at both the undergraduate and graduate level, with disciplines including business, computer networking, and digital forensics. ${ }^{5}$ Champlain College is not unlike many institutions in placing a significant emphasis on online education as a growth market. ${ }^{6}$ Thus, as academic libraries seek to assert, demonstrate, and communicate their value, paying particular attention to the student and faculty populations online will be essential. This paper applies the Academic Library Impact research area on communication to the growing online student and faculty member population, with a particular focus on identifying the preferences for and barriers to communication with the library identified by those patrons.

\section{Literature Review}

Multiple studies explore and assess distance faculty use, need, and perception of library services, which is essential to understanding and addressing the specific needs of campus communities. ${ }^{7}$ These inquiries can lead to better conversation and communication with partners, collaborators, and administration ${ }^{8}$ and, ideally, should also inform evidence-based practice in library offerings, resources, and services. Pitts, Coleman, and Bonella described their data-driven actions arising from a questionnaire with distance education faculty and staff, including changes to reference, instruction, outreach, and collaboration, as well as increased communication with students and faculty. ${ }^{9}$ Through a questionnaire at the University of Victoria, Mussell and Gordon discovered that, while online faculty regarded library services positively, there was a need to make librarians and their services more visible. ${ }^{10} \mathrm{~A}$ multi-institutional assessment of distance instructors across five public research universities found similar results across all institutions. Faculty valued libraries, relied on them to build strong online collections, and used online library research guides in their teaching. Yet barriers to library use included a lack of awareness of the library and its potential offerings for both students and faculty. ${ }^{11}$ Thus, more work needs to uncover how to successfully communicate the library's value and its offerings to online populations.

Asynchronous assistance and online help, keystones of online library communication, can span a range of approaches and topics, leaving librarians with a number of considerations when supporting their online users. Zhang et al. found that online academic library users maintain different expectations for online help. ${ }^{12}$ Some users preferred conceptual help, while others desired procedural, step-by-step help; there is no one-size-fits-all approach to asynchronous online support. The preference for conceptual or theoretical help often changes based on the specific information needs, which Zhang et al. argue creates complexity for the librarian. Library users do respond positively to some common characteristics of online help including comprehensive information offerings, participatory or even crowd-sourced tools, and assistance that is easy to access during the research process. 
Research on online library instruction also provides useful insights that can inform communication initiatives. Librarians employ a number of different curricular approaches varying in terms of breadth, scalability, depth, and personalization to engage students through online instruction. Homol investigated three approaches - asynchronous video tutorials, web research consultations, and live library webinars recorded for later viewing - and found the webinars to be the most time-effective instructional strategy for the impact, measured by number of students reached. ${ }^{13}$ The webinars, tailored to specific assignments, contained the most relevant information for students, and Homol suggests more targeted placement of specific tutorials could increase their use. Librarianship can be embedded within a learning management system (LMS), a more tailored and time-intensive instructional approach that provides point-of-need services and efficient access to customized library resources. Tumbleson and Burke detailed their embedded program and outline sustaining practices for embedded librarianship in online education, noting that "research action no longer swirls around the reference desk nor the library Web site, but in students' online learning space...."14 Taken together, these findings demonstrate the importance of specific, contextualized library communication and of meeting students through the modalities that they are already using.

Rempel and McMillen at Oregon State University detailed another communication strategy, an online library workshop for students replicating the experience and environment of an in-person workshop. ${ }^{15}$ This online literature review workshop was delivered asynchronously to increase accessibility for distance students and was made available for a limited time period to match a typical workshop format. Though their approach was successful, Rempel and McMillen pointed out that online workshops do not provide the same opportunity for students to ask direct questions, work synchronously on their projects, or troubleshoot an unsuccessful search with a librarian. One solution for this could be the use of synchronous online sessions to work with students one-on-one through their search process. ${ }^{16}$ Librarians should consider what aspects of traditional, in-person communication can be successfully reproduced or repurposed in online environments.

Workshops or professional development courses that communicate information literacy components or develop skills with online faculty also emerge repeatedly in the literature. In one case study, Miller et al. of the University of Maryland University College taught information literacy and library skills competencies to online instructional faculty by way of asynchronous online workshops. ${ }^{17}$ These workshops covered topics such as information literacy standards and library services and would be customized to the needs of specific academic departments. A second online library workshop case study identified several important learning objectives for the instructional faculty who participated, such as designing an effective library assignment and understanding information literacy concepts. ${ }^{18}$ Workshops can provide two-way communication between librarians and online faculty, which may result in more effective, efficient, and tailored information and understanding for both parties.

Though many studies conclude that their online and distance patron communities would benefit from stronger marketing and communication from the library, little scholarship focuses on the best ways to do so. To inform these decisions, librarians need to better understand the online populations' communication preferences as well as the barriers impeding efficient and effective communication channels. This study attempts to fill this gap by examining what online students and faculty desire in library communication, as well as what may impede this communication. 


\section{Methodology}

This study employed a mixed methods sequential exploratory design, consisting of a qualitative phase followed by a quantitative phase.$^{19}$ In this design, the themes that emerged in qualitative online focus group discussions informed the development of a questionnaire that was then used to generalize these findings in the second quantitative strand.

The qualitative phase one consisted of online, asynchronous focus groups in Canvas, the college's LMS. After receiving IRB approval, the researchers recruited participants via an email call for participation sent to all online faculty and students at Champlain College. The researchers planned to have two faculty focus groups with six faculty per group and three student focus groups with 10 students per group. These numbers correspond to the findings of Guest, Namey, and McKenna's empirical study on the number of focus groups necessary to reach data saturation. ${ }^{20}$ Both students and faculty self-selected, and the first to respond to the researchers and to complete the online consent forms were chosen to participate.

The focus group method used vignettes, or hypothetical scenarios, which participants discussed and responded to in order to uncover their typical communication behaviors and preferences in different library-related situations. Jenkins et al. discuss the usefulness of this approach in illuminating routine situations or behaviors normally unconsidered by participants. ${ }^{21}$ Recently, Benedetti, Jackson, and Luo argued for the exploration of vignettes in LIS research and outline two useful examples of the methodology in uncovering preferences and behaviors of library patrons. ${ }^{22}$ The vignette scenarios, often based on specific situations the researchers had witnessed, were written to elicit responses to the guiding research questions. Each focus group contained five scenarios with fictional characters in different library-related situations (see appendix A for sample vignettes). Faculty participants and student participants saw somewhat different vignettes and follow-up questions customized to ways in which they may engage with the library and the college. In each situation, participants were asked what they believed the characters would or should do. Participants responded to each situation and also to each other's nonanonymized posts. The focus groups remained open for one week, and participants could return to posts as often as they liked during that time. The researchers reviewed and inductively coded the focus group data for themes. Any discrepancies in coding were discussed and resolved during this process.

The resulting focus group themes, along with specific outstanding questions that the researchers had from the groups themselves, informed the design of the second phase research instrument, a quantitative questionnaire distributed to greater numbers of online students and faculty. Two questionnaires (see appendix B), one for online students and the other for online faculty, were developed from the core themes that emerged from the focus groups. The surveys were delivered through Qualtrics. All online students and faculty members were eligible to participate and were invited via an email campaign and outreach within the LMS. The questionnaire remained open for 11 days. Thirty-four faculty (out of 264 invited) and 136 students (out of 2,624 invited) responded to the questionnaire. In creating a focus-group informed questionnaire with a larger population of respondents, the results from the focus group can be further scrutinized and made generalizable and applicable to other libraries.

\section{Results: Phase I}

Twelve online faculty and 22 online undergraduate and graduate students made up five focus groups that ran over the course of one week. The focus groups responded to different situational vignettes, and participants at times built off and expanded on each other's comments. 


\section{Awareness of Library Services}

Some online faculty members were unaware of potential methods of collaboration with a librarian. Here is one illustrative quote from a faculty participant:

I am personally responsible for the content creation in at least three courses that run online that have replaced a standard textbook with ones freely available in the Champlain Library and on the internet. I was not directed to, nor did I engage a librarian when developing the courses and selecting the supporting materials. While I am confident in the choices made, it would have been great to also have some input from the library.

Similarly, several participants were unaware that they could contact the library directly with library e-resource access problems; some stated that they had learned, either from a librarian-designed professional development course or from their own troubleshooting, how to fix common link errors, while others were more likely to contact the e-learning department within Champlain College Online for assistance.

\section{Perceptions of Student Needs}

The faculty focus groups provided useful information on how faculty perceive their students' library communication needs. As their students are generally very busy people, faculty stressed the importance of students learning when and how to contact a librarian. Further, some advocated for students being able to obtain help at their point of need, which, according to participants, typically falls on nights and weekends. Currently, Champlain College library does not offer any weekend reference support and, as of the spring 2019 semester, weeknight evening reference ends at 9:00 pm Eastern Time. When presented with a vignette of a student who needed research assistance in the middle of the night, some participants mistakenly believed that the student would be able to get in touch with a librarian sometime the next day (Sunday), while others stated that such a service should be available at night. One faculty participant makes the case for weekend reference services, stating, "Considering online students primarily utilize the weekends to focus on their assignments, I think it is reasonable to expect the library... to have weekend contact hours. Even four hours each weekend day would be of great benefit." Other faculty focus group participants, however, did emphasize the importance of students learning when they can contact the library and then deploying time management skills strategically to decrease the likelihood of working on a research-intensive assignment when librarians are unavailable.

Students assumed that, during the library's open hours, the full suite of research help services are available to them. In fact, although a library staff member would be available to speak to them at all times, Champlain College librarians are currently unavailable during late evening hours or weekends. Some student participants suggested that they should be able to communicate with a librarian at any time:

Live help should be available to [a student] 24/7. If Champlain or any college wants to offer an online presence, it should have all of the resources that online students need when they can work. Many adult students are still working and have families and must study when they can set aside the time.... It's just not the 
nature of studying online to not have the resources needed to complete their assignments at ANY time. I don't think students should have to be concerned about the library's staff or hour limitations.

Other participants suggested an on-call model, and a couple believed that the ability to access a reference librarian over nights and weekends was not realistic or necessary.

\section{Benefits of Librarian Assistance}

When presented with a vignette related to a student's reference interaction with a librarian, faculty focus group participants expressed that the interaction likely improved a student's library search skills and the student's confidence in accessing the library. One participant used the metaphor of teaching students how to fish and not just providing a fish to describe the ideal student-librarian reference interaction. Despite this consistently positive impression of student-librarian interaction in the form of reference consultations, some faculty did not identify contacting the library as the primary option that students should pursue when stuck on a research project. In that scenario, participants also identified contacting the course instructor, contacting other students, and independent exploration as options for getting help with a research project.

\section{Communication through the Learning Management System}

Student focus group participants consistently identified the college's LMS, Canvas, as the primary portal through which they access the institution and, as such, preferred that library communication originate from within it. Several students suggested that a Canvas announcement or a direct message from their instructor would be the best way for them to learn about a new library service or resource. One student focus group participant described their relationship with Canvas, noting "...Canvas is life, so I see announcements sent to my Canvas inbox faster than I see those sent to my Champlain email, or even social media. I believe most would prefer the Canvas message or email to receive a message."

\section{Expectations of Reference Help}

Student focus group participants reported that the advantages of contacting a librarian include that the librarian can provide a starting place for a research process, direction for a research process, and tailored, specific help for a research problem. Several participants suggested that the most helpful time to contact a librarian is at the beginning of a research project. At times, some student participants seemed to suggest that the librarian would be or should be the individual conducting the research during a reference consultation, with one participant suggesting that the ideal role of a librarian is as their "research assistant" who "does the legwork to obtain resources that might be useful." Other students stated that they hoped a reference consultation's communication might include the librarian walking a student through relevant library resources and providing tips for how to "vet" information.

In response to a vignette of a reference interaction between a student and a librarian, most student participants, like their faculty members, had a positive impression of the help available to them. While a couple of students questioned the usefulness of a reference librarian in the precise scenario presented in the vignette, other participants rose to the defense of a librarian's ability to assist with a wide range of research situations. 


\section{Results: Phase II}

The researchers used the focus group responses and main findings to develop questions, which were developed into one questionnaire for online faculty (16 questions excluding demographics) and one for online students (15 questions excluding demographics). This process enabled the researchers to survey participants using questions derived from library users' knowledge and ideas, thus using an instrument that more precisely targeted the experiences, needs, and desires of Champlain College's online populations. Further, it expanded the initial phase I findings to determine their applicability to broader populations across the college. Thirty-two faculty members and 133 students responded to their respective online questionnaires in some capacity. However, response rates dropped off slightly as the questionnaire progressed, with most questions on the faculty questionnaire receiving 31 or 32 responses and most questions on the student questionnaire receiving between 120 and 130 responses. Some questions allowed respondents to choose several answers; thus, percentages may exceed 100 percent.

\section{Awareness and Perceived Value of Library Services}

Building on focus group findings, several questions further elicited what faculty already knew or valued about the library and its offerings. Faculty were strongly aware of email (91\%) and phone calls $(81 \%)$, as ways to communicate with the library. Only 25 percent of faculty were aware of online video consultations. Faculty also reported on their prior awareness of potential modes of collaborating with a librarian. The highest number of respondents $(71 \%)$ knew they could receive assistance in selecting library e-books and open access materials for course content, and the fewest respondents $(29 \%)$ reported awareness of the ability to collaborate on assignment or assessment design.

The questionnaire asked faculty to identify the point in a research project that a librarian could be of most use to a student. The most popular choice was "when conducting background research for the topic" (41\%), followed by "when searching for information sources to use in the assignment" (28\%) and "prior to beginning the assignment" (22\%). No faculty participants chose "when evaluating the quality of found information sources" or "when reviewing and completing the project's citations." All participants believed a librarian would be helpful at some stage, with no participants selecting that they did not think a librarian could be of use.

\section{Preferences for Communication Channel, Library Content, and Delivery}

Awareness aligned strongly with recommended channel of communication, with 61 percent of faculty choosing email as the way they would recommend a student contact the library. Only 13 percent recommended live webchat, and only 6 percent recommended an online video consultation.

When ranking resources they prefer to use when they had a question about a task, a majority of faculty $(63 \%)$ choose asking a person as their first choice. Instructional, task-based, written how-to tutorials were a strong second choice, followed by written FAQs, and videos demonstrating the task. Least helpful to faculty was a tool or resource's help manual.

Faculty ranked the importance of several types of librarian online class support from extremely important to not at all important. Overall, faculty found it less important to have a specific librarian to contact, and most important to have a librarian embedded into the LMS course to be available to online faculty and students. However, faculty ranked all types of 
library support relatively high when comparing rankings of moderately important and above to slightly important/not at all important.

When asked about the types of library support that should be available (regardless of what actually is available) to students during off hours (such as 2:30 am on a Sunday), 72 percent of faculty respondents showed interest in expanded asynchronous instructional materials, 50 percent believed there should be additional research help for a few hours on Sunday afternoon, and 41 percent thought there should be a discussion board for students to answer each other's library questions. Only 22 percent reported that there should be training for online faculty members to support students better when librarians are not available.

Faculty showed strong interest in several potential outreach techniques. For example, 59 percent would like to see the library employ a liaison model, with specific librarians with relevant expertise assigned to each program. Fifty percent selected a quarterly newsletter sharing information about new library resources, instructional tools, and initiatives as one of their top options, and 44 percent would like to have regular online workshops to train faculty in Champlain's library resources.

\section{Access to Librarians}

Faculty participants most valued availability of librarians (library/librarians available when needed) over accessibility (multiple types/formats of help), immediacy (receiving help quickly), or efficiency (communicating without too much back-and-forth). Thirty-two percent of all respondents reported that in the last year they had needed to contact a librarian and found them to be unavailable one or more times.

\begin{tabular}{|c|c|c|c|c|c|}
\hline \multicolumn{6}{|c|}{$\begin{array}{c}\text { TABLE } 1 \\
\text { “How much do you value the following in library communication? Rank these qualities in } \\
\text { order from } 1 \text { (most valuable) to } 4 \text { (least valuable)." }\end{array}$} \\
\hline Option & $\begin{array}{c}\text { Mean } \\
\text { Response }\end{array}$ & $\begin{array}{r}1 \text { (Most } \\
\text { Helpful) }\end{array}$ & 2 & 3 & $\begin{array}{l}4 \text { (Least } \\
\text { Helpful) }\end{array}$ \\
\hline $\begin{array}{l}\text { Availability (The library/librarians are available when } \\
\text { I need them) }\end{array}$ & 1.88 & $53 \%$ & $16 \%$ & $22 \%$ & $9 \%$ \\
\hline Immediacy (I receive help quickly from the library) & 2.56 & $22 \%$ & $31 \%$ & $16 \%$ & $31 \%$ \\
\hline $\begin{array}{l}\text { Accessibility (Multiple types/formats of help are } \\
\text { available) }\end{array}$ & 2.66 & $22 \%$ & $19 \%$ & $31 \%$ & $28 \%$ \\
\hline $\begin{array}{l}\text { Efficiency (The communication progresses without } \\
\text { too much back-and-forth) }\end{array}$ & 2.91 & $3 \%$ & $34 \%$ & $31 \%$ & $31 \%$ \\
\hline
\end{tabular}

Overall, faculty responses to questions of impact and effective service suggest a positive brand perception of librarians. Seventy-four percent of faculty believe that the most impactful way for students to learn academic research skills is directly from librarians, and just 10 percent believed it was most impactful for a student to learn through independent exploration on their own. Furthermore, 65 percent of faculty respondents strongly agreed that the library served them as an online faculty member.

\section{Communication Channel Preferences}

When it came to contacting the library, student questionnaire results revealed a gap between 
preferences for and awareness of contact channels. A majority of student respondents were aware that they could email the library $(79 \%)$ or call the library $(52 \%)$, while fewer were aware of communication via a webchat service $(35 \%)$ or that they could hold a research appointment with a librarian over Google Hangouts (17\%). However, when asked for their most preferred method of contacting the library later in the questionnaire, webchat was the choice of about one out of three respondents (33\%), the second most popular choice after email (53\%). This suggests that webchat might be quite popular among students who already know about it or who learned about or were reminded of the service through this questionnaire.

\section{Content, Timing, and Delivery of Library Services}

Students believed that a librarian could be most helpful in the research process when conducting background research on a topic (33\%), when searching for information sources (30\%), or prior to the beginning of the assignment itself (15\%). A smaller share of student respondents said that the best time to contact a librarian was when they were struggling or stuck (12\%). Few respondents believed that the best time to contact a librarian was in the later stages of the research project such as when reviewing citations (1\%). When asked about the methods for learning how to complete a task, students responded most positively to video tutorials (mean answer: 2.68, where 1 was most helpful and 5 was least helpful) and written how-to guides (mean answer: 2.69) and least positively to a tool's help manual (mean answer: 3.49 ) and written FAQs (mean answer: 3.38). It is worth paying particular attention to how students rated "being able to ask a person" (mean answer: 2.75). This option received the largest volume of "most helpful" ratings (37\%) and the second largest volume of "least helpful" ratings $(25 \%)$, suggesting polarized opinions about the importance of human communication when library questions arise.

\begin{tabular}{|c|c|c|c|c|c|c|}
\hline \multicolumn{7}{|c|}{$\begin{array}{c}\text { TABLE } 2 \\
\text { "When I have a question about how to complete a task, I find these types of resources to } \\
\text { be the most helpful in answering it. Rank these qualities in order from } 1 \text { (most helpful) to } \\
5 \text { (least helpful)." }\end{array}$} \\
\hline Option & $\begin{array}{c}\text { Mean } \\
\text { Response }\end{array}$ & $\begin{array}{l}1 \text { (Most } \\
\text { Helpful) }\end{array}$ & 2 & 3 & 4 & $\begin{array}{l}5 \text { (Least } \\
\text { Helpful) }\end{array}$ \\
\hline Videos that demonstrate the task & 2.68 & $24 \%$ & $25 \%$ & $22 \%$ & $17 \%$ & $12 \%$ \\
\hline $\begin{array}{l}\text { Instructional, task-based, written how-to- } \\
\text { tutorials }\end{array}$ & 2.69 & $15 \%$ & $31 \%$ & $32 \%$ & $15 \%$ & $7 \%$ \\
\hline Being able to ask a person & 2.75 & $37 \%$ & $13 \%$ & $13 \%$ & $12 \%$ & $25 \%$ \\
\hline Written FAQs (Questions and answers) & 3.38 & $11 \%$ & $18 \%$ & $14 \%$ & $36 \%$ & $21 \%$ \\
\hline A tool or resource's help manual & 3.49 & $14 \%$ & $12 \%$ & $19 \%$ & $20 \%$ & $35 \%$ \\
\hline
\end{tabular}

Student participants most highly valued the availability of librarians and least valued the efficiency of that communication. Twenty-two percent of student participants reported that, in the last year, they have needed to contact a librarian and found them to be unavailable either because the building was closed or because reference was not being offered.

If a student had questions about the quality of their sources, 55 percent of participants would recommend that the student contact the library first, while 33 percent would recommend that the student contact their instructor first, and 11 percent would recommend that the 
student check out an online video or guide through the library's website. Student participants do feel that the most impactful way to learn information literacy skills is within the context of their course, either through librarian-designed content (53\%), or directly from their course instructor $(36 \%)$.

\section{Student Recommendations for Communication-based Services}

When asked to select up to three services that should be available to students with a reference question at 2:00 am on a Sunday, 24/7 access to a Champlain College research librarian and a fully staffed research help service on Sunday afternoons were, respectively, the first (54\%) and fourth $(40 \%)$ most commonly selected options. Other popular potential services were expanded asynchronous research support tools such as instructional videos (45\%), and a dedicated space where students could ask each other research questions (44\%). The remaining options had smaller constituencies, including time management and planning instruction opportunities for students to help them avoid last-minute research questions (30\%) and better training for students' instructors so that they can better assist students with library-related questions (25\%).

Student participants were asked to choose up to three communication approaches that Champlain College library does not currently use but that would appeal to or engage them. The three most popular options were the use of a subject liaison model (52\%), a quarterly newsletter (45\%), and synchronous online supplemental library workshops (44\%). The least popular option was moving some traditional library outreach and community building activities such as book groups into an online environment (16\%).

\section{Discussion}

This mixed-methods study resulted in a number of relevant insights into our online students' and faculty communication preferences and barriers. Faculty in particular repeatedly expressed a strong desire for person-to-person communication with librarians. Respondents placed a high value on faculty-librarian collaboration, with multiple focus group participants stating that either they would try to work with the library when preparing courses in future semesters or that they regretted not realizing that they could contact the library for help with course development in the past. This belief carries over to the value, expressed in the questionnaire, that faculty placed on students learning research skills directly from librarians.

Students reported the most impactful way to learn information literacy skills was through integration into their online courses. While this seamless model works well for students, it has specific implications for library communication. Our current online library instruction modules are embedded into the online course and are delivered by the online faculty. This model renders librarians somewhat invisible and may also result in students being less likely to communicate with librarians when they need help. These findings also reveal several opportunities. Librarians could create and run more faculty development opportunities to increase their information literacy skills. Librarians could also be more strategic in finding ways for students to "know" them, such as personal bios and contact information embedded directly into the LMS course.

Results show that both online students and faculty value the availability of librarians. The timing and amount of availability also matters to these populations. During both phases of the study, faculty and students expressed a desire for librarian services to be expanded, sometimes quite dramatically. However, only a minority of phase II respondents reported that they had 
actually been unable to contact a librarian at a time of need. The questionnaire did not ask those respondents about the ultimate outcome of their information need; some respondents may have found a librarian unavailable when a question first arose but were nonetheless able to get assistance quickly enough to complete an assignment. Champlain College library reduced reference service hours of availability in the fall 2019 semester, partially due to low service utilization in the evening. The source of this disconnect between reported service need and observable service usage is worthy of further study at this institution and others.

When asked about potential outreach techniques, both faculty and student respondents reported interest in liaison models where librarians had expertise in specific programs' research methods and instructional materials. In seeming contradiction, faculty also reported having a specific librarian to contact as less important than having a librarian embedded into the online course. This suggests that faculty most desire easy, course-integrated access to librarians with subject-specific expertise but that they care less about knowing an exact librarian to contact outside of that course. While one coauthor of this paper leads efforts to integrate information literacy instruction into the online curriculum, all Champlain College librarians are generalists, and there is often not one library employee in particular that a faculty member or a student should be contacting directly. As many Champlain College online classes are practitioner-led, being taught by working professionals in their field, the college's online population may place a particularly high level of value on subject-specific expertise, thus concluding that access to a librarian who shared this subject-matter expertise would improve communication. Shifting to a liaison-based online structure would be a significant organizational challenge for the Champlain College Library and is not under consideration at this time, but these findings might confirm the advantages of this structure at other institutions.

One barrier to communication that emerged for both study populations was lack of knowledge of communication channels and library services available to them. While most participants had some awareness of library communication opportunities, such as emailing a librarian, they generally lacked knowledge of the full range of communication channels or scenarios in which one might contact the library. One solution may be to make these communication channels more visible. The easiest way to learn about web chat is to visit the library's website, and there is a prominent link to the library's homepage within the LMS navigation. However, the library's phone number can be easily found via search engines, and a user can easily find library email addresses via the campus email portal. The library is also unusual for a campus service in offering chat and Google Hangouts; phone and email are the main ways that off-campus college affiliates contact on-campus offices. Techniques for making library webchat and web conferencing more visible to online users, such as embedding chat and conference scheduling services deeper into the LMS could reduce communication barriers.

As a result of this study, Champlain College Library plans to prioritize adjustments that increase visibility of librarians and communication opportunities with them. In the summer of 2019, an Outreach and Engagement Librarian position was created and filled. This position now includes specific outreach duties to engage and connect with Champlain College Online. Further, our instructional focus is expanding to consider how all librarians, not just our one Digital Learning Librarian, can play more integrated roles in the quickly expanding online instructional program. We have also prioritized an online faculty development course on using library resources in their courses and plan to participate in additional faculty outreach opportunities in the spring of 2020, such as online "lunch and learns." 
This study's methodology provided a unique way to elicit faculty and student voice. Qualitative vignettes allowed focus group respondents to speak to their habitual and possibly unconsidered behaviors in different situations. The sequential exploratory mixed methods design allowed the creation of the second quantitative phase from the first qualitative phase; the questionnaire thus reflected the views and voices of our online populations rather than an "off-the-shelf instrument." ${ }^{23}$ Surveying the broader online populations helped to determine generalizability and case-to-case transfer of findings as well as the potential of transferability to other academic libraries serving online learners.

Engaging in research with the community can itself be an intervening tool of change. Several participants in the focus groups, both students and faculty, remarked that they were learning more about the library solely through participation in the study. After reading a vignette about ways in which a faculty member might collaborate with a librarian, one faculty participant who had not previously realized there were so many options for collaboration stated this: "I am so glad to have the ways that we can communicate! As a course owner/ developer, I had no idea of the support available through finding resources and thought that was incredibly helpful to learn." This suggested that the research itself may have served as a highly impactful outreach activity.

\section{Limitations}

As participants were self-selected for both stages of data collection, we may not have had a representative sample. For instance, participants may have had differing levels of library experience or involvement, or they may have had a vested interest in the library that could have influenced their responses.

\section{Conclusion}

This study provided a number of important findings related to online faculty and students' preference for and barriers to communication with the library. One overarching revelation of this study was the importance of reaching out to and communicating with these patron populations in the first place. As lack of knowledge of services serves as a significant communication barrier, and as some communication opportunities are highly appealing to these populations once they are introduced or modeled, activities that initiate the conversation between library and online populations can be groundbreaking. Further, this study revealed a disconnect between reported service need and observable service usage, suggesting inaccurate communication both from patrons on their actual needs and from the library on their actual services. It also raises consideration around the tension between seamless integration of library service and instruction that facilitates ease of access for online end-users but decreases librarian visibility. In increasingly prominent online environments, these considerations will be crucial for providing exemplary library service to all patrons. 


\section{APPENDIX A. A Partial Sample of Vignettes and Questions Used for Phase I Focus Groups}

\section{Vignette 1}

Objective: To understand what point during a research project students identify as the time to contact a librarian.

Vignette: Kim, Rafael, and Sara are students in the Master of Science in Executive Leadership program, and their instructor assigned them to complete an annotated bibliography as a group on the theory of Transactional Leadership. They then start looking for resources to complete their annotated bibliography, which requires at least 10 academic sources, four of which must be written by authors that they identify as important or foundational theorists on Transactional Leadership. They start out by reviewing their textbook and searching Google for definitions of and key theorists on Transactional Leadership. With a few search terms in hand, Kimberly looks for books at her local public library and articles on Google Scholar. Rafael searches on Google and Google Books. Sara uses the Academic Search Complete database from the Champlain College Library to search for articles and books. The three of them have a virtual meeting in which they share the sources that they found. Technically, they have 10 sources, but they only know for sure that one of them is written by an important theorist. They also recently saw an announcement from their instructor reminding students in the class that their sources need to either be scholarly or otherwise written by an expert on the topic, and they are not sure how many of their sources qualify.

Questions: At what point during this vignette, if any, would you advise Kimberly, Rafael, and Sara to contact the Champlain College library? What would be the best way for them to initiate this contact? How do you think that Kimberly, Rafael, and Sara should proceed in trying to determine whether or not their resources would be considered scholarly by their instructor?

\section{Vignette 2}

Objective: To identify how students and faculty respond to communication barriers with the library.

Vignette: It's 2:45 am Eastern Time on a Sunday morning, and Mark is stuck on an assignment in his Marketing class that requires library research. He visited the library's website and looked at the Article databases page and the eJournals by Title page, but is unsure of which link on those pages to follow. He figures that the library is closed right now and is not sure whether it will be open again before his assignment is due later that day.

Questions: Regardless of what you think is currently available, what should be available to Mark in this scenario? How should Mark proceed in getting help? If Mark contacted you to ask for advice in this situation, what would you suggest that he do to get help?

\section{Vignette 3}

Objective: To discover what online students and faculty understand of library staff roles and job duties.

Vignette: Oscar is studying project management and was recently assigned to compile data about the insurance industry to support a case study. As one component of this assignment, his instructor has suggested that each student should consider meeting with a librarian over Google Hangouts. Oscar hasn't ever worked with a librarian before and isn't sure what to expect.

Questions: What do you imagine that the librarian has to offer from this meeting? How do you think this meeting might be helpful? What would you hope the librarian could offer if it was the best and most useful meeting that you could imagine? 


\section{APPENDIX B. A Partial Sample of Questions Asked on the Phase II Questionnaires}

Asked to both faculty members and to students:

At what point during a research project that requires academic sources do you think a Champlain College librarian could be of most use to a student? (Choose one)

- Prior to beginning the assignment

- When conducting background research for the topic

- When searching for information sources to use in the assignment

- When evaluating the quality of found information sources

- When integrating the information from the sources into the project

- When reviewing and completing the project's citations

- When and if struggling or stuck

- At another time

- I do not think that a Champlain College librarian would be useful to a student working on a research project.

When I have a question about how to complete a task, I find these types of resources to be the most helpful in answering it. Rank these qualities in order from 5 (most helpful) to 1 (least helpful).

- Being able to ask a person

- Instructional, task-based, written how-to tutorials

- Videos that demonstrate the task

- Written FAQs (Questions and answers)

- A tool or resource's help manual

It's 2:30 am Eastern Time on Sunday morning, and (you are/one of your students is) stumped on an assignment that requires research and is due that Sunday evening. Regardless of what you believe is currently available to (you/this student), what should be available? (Check up to three options)

- 24/7 Research Help Service from Champlain College librarians

- Research Help Service for a few hours on Sunday afternoons from Champlain College librarians

- Expanded asynchronous instructional materials (videos, how-to guides, and the like)

- Training for Champlain College Online faculty members so they can better support students when librarians are not available

- Spaces for students to answer each other's library questions

- Better time management instruction for students so they can anticipate potential roadblocks in the research process

In the last year, approximately how many times have you needed to contact a Champlain College librarian and found them to be unavailable (for example, because the library was closed, or the library was open but a librarian was not available)? (Select one)

- Zero

- Once

- Twice

- Three or more times 
Asked to faculty members only:

Which of these methods of contacting the library for research help or database (such as ProQuest, EBSCO, or JSTOR) help were you aware of prior to taking this survey? (Check all that apply)

- Email a Champlain College librarian

- Live webchat with a Champlain College librarian

- Phone call to Champlain College Library

- Schedule an appointment with a Champlain College librarian via Google Hangouts

- Locate a Champlain College librarian in the Faculty Lounge Canvas course and send a Canvas message

Below are some techniques that academic libraries use to engage off-campus/online faculty and students. Which of these would you like to see the Champlain College Library use to engage you and your students? (Select up to three)

- A quarterly newsletter sharing information about new library resources, instructional tools, and initiatives in the library

- Regular online workshops to train faculty in Champlain's library resources

- A specific librarian assigned to each program who has expertise in that program's research methods and instructional materials

- Traditional library programming such as book discussion groups that cater to online/ off-campus users

- Technical support in developing Open Educational Resources

- Microgrants to support faculty developing information literacy-informed assignments

- A student library advisory council that meets with the library to improve the student experience, provide input and feedback, and evaluate library impact

- A faculty library advisory council that meets with the library to deepen librarian/faculty collaboration, provide input and feedback, and evaluate library impact

Asked to students only:

Which of these methods of contacting the library for research help or database help (such as ProQuest, EBSCO, JSTOR, or others) were you aware of prior to taking this survey? (Check all that apply)

- Email a Champlain College librarian

- Live webchat with a Champlain College librarian

- Phone call to Champlain College Library

- Schedule an appointment with a Champlain College librarian via Google Hangouts

Below are some techniques that academic libraries use to engage off-campus/online faculty and students. Which of these would you like to see the Champlain College Library use to engage you? (Select up to two)

- A quarterly newsletter sharing information about new library resources, instructional tools, and initiatives in the library

- A specific librarian assigned to each program who has expertise in that program's research methods and instructional materials

- Traditional library programming such as book discussion groups that cater to online/ off-campus users 
- A student library advisory council that meets with the library to improve the student experience, provide input and feedback, and evaluate library impact

- A librarian placed into classes that have a research component who is available to answer questions or contribute to class discussions

- Live, online workshops with librarians covering research and library skills

\section{Notes}

1. Association of College and Research Libraries (ACRL), Academic Library Impact: Improving Practice and Essential Areas to Research, prepared by Lynn Silipigni Connaway, William Harvey, Vanessa Kitzie, and Stephanie Mikitish of OCLC Research (Chicago, IL: ACRL, 2017).

2. ACRL, Academic Library Impact.

3. Mark Lieberman, "Online Tuition Too High? Cut It in Half," Inside Higher Ed (Apr. 17, 2019), available online at https:/www.insidehighered.com/digital-learning/article/2019/04/17/champlain-college-slashes-undergraduateonline-tuition-half [accessed 23 July 2019]; Champlain College, "Champlain College I Quick Facts I Colleges in Vermont," available online at https://www.champlain.edu/about-champlain/quick-facts-and-history [accessed 25 July 2019].

4. Lieberman, "Online Tuition Too High?"

5. Champlain College, "Accredited and Affordable Online Degree Completion Programs I Champlain College Online," available online at https://www.champlain.edu/online/degrees-and-certificates [accessed 8 October 2019].

6. Lieberman, "Online Tuition Too High?"

7. Kay Shelton, "Library Outreach to Part-Time and Distance Education Instructors," Community \& Junior College Libraries 15, no. 1 (Jan. 2009): 3-8, https://doi.org/10.1080/02763910802656812; Joelle Pitts, Jason Coleman, and Laura Bonella, "Using Distance Patron Data to Improve Library Services and Cross-Campus Collaboration," Internet Reference Services Quarterly 18, no. 1 (Jan. 2013): 55-75, https://doi.org/10.1080/10875301.2013.800014.

8. Jessica Mussell and Carol Gordon, "Uncovering the Evidence: Faculty Perceptions of Distance Library Services," Journal of Library \& Information Services in Distance Learning 11, no. 3/4 (Oct. 2, 2017): 271-86, https://doi. org/10.1080/1533290X.2017.1347121.

9. Pitts, Coleman, and Bonella, “Using Distance Patron Data to Improve Library Services and Cross-Campus Collaboration."

10. Mussell and Gordon, "Uncovering the Evidence."

11. Cassandra Kvenild et al., "Multi-Institutional Assessment of Distance Instructors: High Satisfaction, Low Knowledge of Library Services," portal: Libraries and the Academy 18, no. 4 (Oct.8, 2018): 719-36, https://doi. org/10.1353/pla.2018.0042.

12. Tao Zhang, Ilana Stonebraker, and Marlen Promann, "Understanding Library Users' Preferences and Expectations of Online Help," Reference Services Review 44, no. 3 (2016): 362-74, https://doi.org/10.1108/RSR-12-2015-0054.

13. Lindley Homol, "Two Thousand Students, One Librarian: Balancing Depth and Breadth of Library Instruction for Online Graduate Students," Journal of Library \& Information Services in Distance Learning 12, no. 3/4 (Oct. 2, 2018): 250-58, https://doi.org/10.1080/1533290X.2018.1498637.

14. Beth E. Tumbleson and John J. Burke, "When Life Hands You Lemons: Overcoming Obstacles to Expand Services in an Embedded Librarian Program," Journal of Library Administration 50, no. 7/8 (Oct. 2010): 974, https:// doi.org/10.1080/01930826.2010.489002.

15. Hannah Gascho Rempel and Paula S. McMillen, “Using Courseware Discussion Boards to Engage Graduate Students in Online Library Workshops," Internet Reference Services Quarterly 13, no. 4 (Oct. 2008): 363-80, https://doi.org/10.1080/10875300802326350.

16. Gascho Rempel and McMillen, "Using Courseware Discussion Boards to Engage Graduate Students in Online Library Workshops," 376.

17. Robert Miller et al., "Library-Led Faculty Workshops: Helping Distance Educators Meet Information Literacy Goals in the Online Classroom," Journal of Library Administration 50, no. 7/8 (Oct. 2010): 830-56, https:// doi.org/10.1080/01930826.2010.488977.

18. Erin McCaffrey, Tina J. Parscal, and Tom Riedel, "The Faculty-Library Connection: An Online Workshop," Journal of Library Administration 45, no. 1/2 (Nov. 2006): 279-300, https://doi.org/10.1300/J111v45n01_16.

19. John W. Creswell and Vicki L. Plano Clark, Designing and Conducting Mixed Methods Research, 2nd ed. (Los Angeles, CA: SAGE Publications, 2011). 
20. Greg Guest, Emily Namey, and Kevin McKenna, "How Many Focus Groups Are Enough? Building an Evidence Base for Nonprobability Sample Sizes," Field Methods 29, no. 1 (Feb. 2017): 3-22, https://doi. org/10.1177/1525822X16639015.

21. Nicholas Jenkins et al., "Putting It in Context: The Use of Vignettes in Qualitative Interviewing," Qualitative Research 10, no. 2 (Apr. 1, 2010): 175-98, https://doi.org/10.1177/1468794109356737.

22. Allison Benedetti, John Jackson, and Lili Luo, “Vignettes: Implications for LIS Research," College E Research Libraries 79, no. 2 (2017): 222-36, https://doi.org/10.5860/crl.79.2.222.

23. John W. Creswell, Michael D. Fetters, and Nataliya V. Ivankova, "Designing A Mixed Methods Study in Primary Care," Annals of Family Medicine 2, no. 1 (Jan. 2004): 11, https://doi.org/10.1370/afm.104. 